\title{
Clinicopathologic and Molecular Characteristics of Mesonephric Adenocarcinoma Arising From the Uterine Body
}

\author{
Kiyong Na, MD, PhD and Hyun-Soo Kim, MD, PhD
}

\begin{abstract}
Mesonephric adenocarcinoma (MNAC) is a rare tumor of the female genital tract mainly occurring in the uterine cervix. To date, only a few cases of MNAC arising from of the uterine body (UB-MNAC) have been reported. The clinicopathologic and molecular characteristics of UB-MNAC remain unknown. In this study, we investigated the clinical, histopathologic, immunohistochemical, and genetic features of UB-MNAC. In total, 11 cases were included. Six patients developed metastatic disease, most commonly in lungs (5/6). Histopathologically, UB-MNAC was characterized by an admixture of tubular, glandular, papillary, retiform, glomeruloid, sex cord-like, and comedonecrosis-like architectural patterns. Three adverse pathologic characteristics, including advanced International Federation of Gynecology and Obstetrics stage, high mitotic activity, and presence of lymphovascular the invasion, were independent factors predicting the development of metastasis. All cases were positive for GATA-binding protein 3 and paired box 2 expression and showed wild-type p53, patchy p16, and preserved PTEN expression, as indicated by immunohistochemistry. Next-generation sequencing using 12 samples (11 primary tumors and 1 metastatic tumor) revealed 42 single nucleotide variations in 16 genes, mostly in $K R A S(10 / 12)$ and $A R I D I A(9 / 12)$. Copy number variation was found in 16 genomic regions, and consisted of 57 gains and 10 losses, with 1q gain (11/12) being the most prevalent. In conclusion, UB-MNAC displays an aggressive biological behavior, with a tendency to metastasize to the lungs. Adverse pathologic characteristics
\end{abstract}

From the Department of Pathology, Severance Hospital, Yonsei University College of Medicine, Seoul, Republic of Korea.

Conflicts of Interest and Source of Funding: Supported by Basic Science Research Program through the National Research Foundation of Korea (NRF) funded by the Ministry of Education (2016R1D1A1B03935584 to H.-S.K.). The authors have disclosed that they have no significant relationships with, or financial interest in, any commercial companies pertaining to this article.

Correspondence: Hyun-Soo Kim, MD, PhD, Department of Pathology, Severance Hospital, Yonsei University College of Medicine, 50-1, Yonsei-ro, Seodaemun-gu, Seoul 03722, Republic of Korea (e-mail: hyunsookim@yuhs.ac).

Supplemental Digital Content is available for this article. Direct URL citations appear in the printed text and are provided in the HTML and PDF versions of this article on the journal's website, www.ajsp.com.

Copyright (C) 2017 The Author(s). Published by Wolters Kluwer Health, Inc. This is an open-access article distributed under the terms of the Creative Commons Attribution-Non Commercial-No Derivatives License 4.0 (CCBY-NC-ND), where it is permissible to download and share the work provided it is properly cited. The work cannot be changed in any way or used commercially without permission from the journal. reflect the aggressive nature of UB-MNAC. Distinct molecular features of UB-MNAC include frequent somatic mutations of $K R A S$ and $A R I D 1 A$ and gain of 1q.

Key Words: uterine body, mesonephric adenocarcinoma, metastasis, next-generation sequencing, KRAS, ARIDIA, 1q gain

(Am J Surg Pathol 2019;43:12-25)

$M$ esonephric adenocarcinoma (MNAC) is a rare malignant tumor that originates from mesonephric remnants of the female genital tract. ${ }^{1}$ MNAC is histopathologically characterized by a combination of diverse growth patterns showing tubular, glandular, papillary, retiform, and glomeruloid architecture, and a has a distinctive immunophenotype. ${ }^{2}$ MNAC exhibits positive immunoreactivity for GATAbinding protein 3 (GATA3), paired box 2 (PAX2), and CD10, and negative reactivity for hormonal receptors. ${ }^{3-6}$ Mesonephric remnants are typically located in the cervical stroma and adjacent to the ovaries, fallopian tube, and broad ligament, although they may rarely occur in the vaginal wall or myometrium. ${ }^{7}$ Previous studies have documented that mesonephric remnant in any location can be the origin of MNAC. Although most cases of MNAC are found in the uterine cervix (UC), ${ }^{2,8,9}$ several cases of MNAC arising from the ovaries, vagina, and uterine corpus have been reported. ${ }^{5,10-19}$

The pathogenesis of MNAC remains unknown. MNAC shows preserved phosphatase and tensin homolog deleted on chromosome 10 (PTEN) expression, wild-type p53 expression pattern, and nondiffuse p16 expression, indicating that this rare tumor exhibits immunohistochemical and molecular features different from those of endometrial endometrioid and serous carcinoma and usual-type endocervical adenocarcinoma. A recent study that used next-generation sequencing (NGS) for targeted genomic profiling reported that the majority of MNAC examined harbored $K R A S$ mutation, ${ }^{20}$ suggesting that $K R A S$ mutation is involved in MNAC development.

Most patients with MNAC of the UC(UC-MNAC) present at International Federation of Gynecology and Obstetrics (FIGO) stage I. Distant metastases at initial diagnosis are detected in $\sim 5 \%$ of UC-MNAC patients. ${ }^{9}$ Thirty-two percent of FIGO stage I UC-MNAC patients develop recurrence even after curative resection. ${ }^{9}$ This rate of recurrence is substantially higher than that of FIGO stage I cervical squamous cell carcinoma $(11.0 \%)$ and usual-type endocervical adenocarcinoma $(16.0 \%),{ }^{21}$ suggesting that 
patients with UC-MNAC have a worse prognosis than those with more common types of cervical carcinoma. Because of the limited number of cases reported, less is known regarding the clinical outcomes of MNAC arising from the uterine body (UB-MNAC). Most publications on UB-MNAC are individual case reports. ${ }^{10-18}$ Although some case series have described the clinicopathologic characteristics of MNAC, they dealt with only a few cases of UB-MNAC. $3,6,20,22$

We recently identified some cases of UB-MNAC in postmenopausal women who developed distant metastases. Upon a thorough literature review, we recognized that approximately half of the patients with UB-MNAC develop metastatic disease. This finding led us to investigate the clinical outcomes of UB-MNAC diagnosed in our institution. In this study, we analyzed the clinical characteristics, histopathologic features, and immunohistochemistry of UB-MNAC. Using NGS technology, we investigated the molecular genetic alterations associated with UB-MNAC.

\section{MATERIALS AND METHODS}

\section{Case Selection}

Following approval (4-2017-0837) by the Institutional Review Board at the Severance Hospital (Seoul, Republic of Korea), the pathology database was queried for all cases of UB-MNAC between 2012 and 2017. The inclusion criteria were: (1) histopathologically confirmed MNAC; (2) no involvement of the UC and low uterine segment; and (3) tumor epicenter within the myometrium of the UB. Eleven cases of UB-MNAC were included in this study. For each case, all slides were available for review.

\section{Medical Record Review}

All patients were treated and monitored at the Department of Obstetrics and Gynecology, Severance Hospital (Seoul, Republic of Korea). We thoroughly reviewed patients' medical records, pathology reports, and gross photographs. Clinical details, including age at initial diagnosis, presentation of symptoms and/or signs, serum cancer antigen (CA)-125 level, preoperative endometrial curettage diagnoses, surgical treatment, FIGO stage, postoperative treatment, response to chemotherapy and/or radiation therapy, development of recurrence and/or metastasis, progression-free and overall survival, and current status were examined. The pathologic characteristics reviewed included tumor size, border, architectural pattern, and invasion depth; presence of sarcomatous component; coagulative tumor cell necrosis and lymphovascular invasion; degree of nuclear atypia; and mitotic count per 10 high-power fields.

\section{Pathologic Examination}

Formalin-fixed, paraffin-embedded (FFPE) blocks of surgical resection specimens were cut into $4-\mu \mathrm{m}$ sections and stained with hematoxylin and eosin. Two independent pathologists specialized in gynecologic oncology examined all available stained slides by routine light microscopy and selected the most representative FFPE block for immunohistochemical staining and NGS analyses.

\section{Immunohistochemistry}

The FFPE tissue sections were deparaffinized in xylene and rehydrated through graded ethanol series. Immunohistochemical staining was conducted using the Ventana Benchmark XT automated staining system (Ventana Medical Systems, Tucson, AZ) or Dako Omnis (Dako, Carpinteria, $\mathrm{CA}$ ), according to the manufacturer's recommendations. Antigen retrieval was achieved using Cell Conditioning Solution (CC1; Ventana Medical Systems) or EnVision FLEX Target Retrieval Solution, High pH (Dako). The sections were subsequently incubated with primary antibodies against calretinin (1:100, polyclonal; Cell Marque, Rocklin, CA), CD10 (1:50, clone 56C6; Novocastra, Leica Biosystems, Newcastle Upon Tyne, UK), cytokeratin 7 (1:100, clone OV-TL 12/30; Dako), estrogen receptor (ER, 1:150, clone 6F11; Novocastra), GATA3 (1:150; Cell Marque), p16 (prediluted, clone E6H4; Ventana Medical Systems), p53 (1:300, clone DO-7; Novocastra), PAX2 (1:1000, clone EP3251; GeneTex, Irvine, CA), progesterone receptor (PR; 1:100; clone 16; Novocastra), and PTEN (1:100, clone D4.3; Cell Signaling Technology, Danvers, MA). After chromogenic reaction using an ultraView Universal DAB Detection Kit (Ventana Medical Systems) or an EnVision FLEX /HRP Kit (Dako), the slides were counterstained with hematoxylin. The p53 immunostaining pattern was interpreted as a missensemutation, nonsense-mutation, or wild-type pattern when p53 expression was diffuse and strong ( $>60 \%$ of tumor cell nuclei), absent $(<5 \%)$, or focal and weakly positive, respectively. The p16 immunostaining pattern was interpreted as positive (diffuse) when p16 expression was continuous and strong, nuclear or nuclear plus cytoplasmic staining. All other p16 immunostaining patterns, described as focal nuclear staining or wispy, blob-like, puddled, or scattered cytoplasmic staining, were interpreted as negative (patchy). ${ }^{23}$

\section{Next-generation Sequencing}

Genomic DNA was extracted using a QIAamp DNA FFPE Tissue Kit (Qiagen, Valencia, CA). Using genomic DNA, coding exons and their flanking regions of 82 genes (Supplementary Table 1, Supplementary Digital Content 1, http://links.lww.com/PAS/A567) were enriched using the SureSelectXT Reagent Kit (Agilent Technologies, Santa Clara, CA). The products were sequenced on a HiSeq 2500 System (Illumina, San Diego, CA) using paired-end reads. The reads were aligned to a reference genome sequence (version hg19) obtained from the University of California Santa Cruz Genome Browser database (https://genome.ucsc.edu/), ${ }^{24}$ and duplicate reads were removed. Burrows-Wheeler AlignerMEM (http://bio-bwa.sourceforge.net), SAMtools (http:// samtools.sourceforge.net/), Picard Tools (http://broadinstitute. github.io/picard/), and GATK (https://software.broadinstitute. org/gatk/) were used for sorting Sequence Alignment Map/ Binary Alignment Map files, duplicate marking, and local realignment, respectively. Local realignment and base recalibration were carried out using dbSNP (www.ncbi.nlm.nih.gov/ projects/SNP/), Mills indels, ${ }^{25}$ HapMap, and Omni. Single nucleotide variants (SNVs) and insertions and deletions (indels) were identified using MuTect (http://archive.broadinstitute.org/ cancer/cga/mutect) and Pindel (http:/gmt.genome.wustl.edu/ 


\section{Preoperative}

Diagnosis

CA

ymptom/Sign $\quad(\mathrm{U} / \mathrm{mL})$

Curettage

Surgical FIGO

Stage

Postoperative Clinical Course

PFS OS Current

Treatment

Stage

No postoperative treatment

(mo) (mo) Status

LN metastasis

$\begin{array}{lll}4 & 8 & \text { DOD }\end{array}$

LN metastasis
CTx (cisplatin+cyc

$\begin{array}{ccccccc}2 & 2001^{11} & 33 & \text { LAP } & 47.0 & \text { NA } & \begin{array}{c}\text { TH+BSO+PLND } \\ 3\end{array} \\ 2003^{12} & 33 & \text { LAP } & 41.0 & \text { NA } & \begin{array}{c}\text { TH+BSO+PLND } \\ + \text { PALND }\end{array} \\ & & & & & & \\ 4 & 2004^{13} & 37 & \text { Vaginal bleeding } & \text { NA } & \text { NA } & \begin{array}{c}\text { TH+BSO } \\ 5\end{array} \\ & 2006^{14} & 81 & \text { Vaginal bleeding } & 55.0 & \text { MNAC } & \begin{array}{c}\text { TH+BSO+PLND } \\ + \text { PALND }\end{array} \\ 6 & 2008^{15} & 73 & \text { Multiple pulmonary } & \text { WNL } & \text { NA } & \text { TH+BSO }\end{array}$

\section{IB RTx}

RTx
No specific event

IB RTx

rese

Lung, abdomen, and perihepatic LN

CTx (carboplatin+paclitaxel, 12 cycles) Partial response

No postoperative treatment

No specific event

IB No postoperative treatment

No specific event

IVB CTx (carboplatin+paclitaxel)

Increased size of lung metastasis

and abdominal recurrence

CTx (carboplatin+paclitaxel)

Stable disease

$7 \quad 2014^{16} \quad 55 \quad$ Vaginal bleeding NA

$8 \quad 2014^{16} \quad 62 \quad$ Vaginal bleeding NA

$9 \quad 2016^{17} \quad 66 \quad$ Vaginal bleeding WNL

$\begin{array}{llll}10 & 2016^{18} & 55 & \text { Vaginal bleeding }\end{array} \quad 163.8$

MNAC

$\mathrm{TH}+\mathrm{BSO}+\mathrm{PLND}$

MNAC

$\mathrm{TH}+\mathrm{BSO}+\mathrm{PLND}$

EC

$\mathrm{TH}+\mathrm{BSO}+\mathrm{PLND}$

AC with sarcomatous feature

$\mathrm{TH}+\mathrm{BSO}+\mathrm{PLND}$

MNAC

TH+BSO+PLND

EC

TH+BSO+PLND

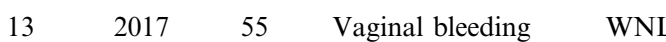

NA

Vaginal bleeding
WNL
+ PALND

$\mathrm{TH}+\mathrm{BSO}$

IB No postoperative treatment

No specific event

IB No postoperative treatment

No specific event

IB No postoperative treatment

No specific event

II CTx (cisplatin+paclitaxel, 4 cycles)

Mediastinal LN metastasis, abdominal

recurrence, and elevated CA-125

CTx (pirarubicin+cisplatin+ifosfamide)

IIIC RTx+CTx (cisplatin+docetaxel)

No specific event

IIIB RTx + CTx (carboplatin+paclitaxel, 3 cycles)

Lung metastasis

CTx (carboplatin+paclitaxel, 3 cycles)

Stable disease

IVB RTx+CTx (carboplatin+paclitaxel, 6 cycles) Partial response CTx (carboplatin+paclitaxel, 6 cycles)

Increased size of lung metastasis and elevated CA-125

CTx (carboplatin+paclitaxel, 9 cycles)

Stable disease

$\mathrm{TH}+\mathrm{BSO}$

III

RTx +CTx (carboplatin+paclitaxel, 6 cycles)

$\begin{array}{rrr}\text { NA } & 8 & \text { NED } \\ 10 & 22 & \text { AWD }\end{array}$

$\begin{array}{crr}\text { NA } & 45 & \text { NED } \\ \text { NA } & 9 & \text { NED } \\ 6 & 28 & \text { AWD }\end{array}$

$\begin{array}{crr}\text { NA } & 7 & \text { NED } \\ \text { NA } & 1 & \text { NED } \\ \text { NA } & 2 & \text { NED } \\ 8 & 12 & \text { DOD }\end{array}$




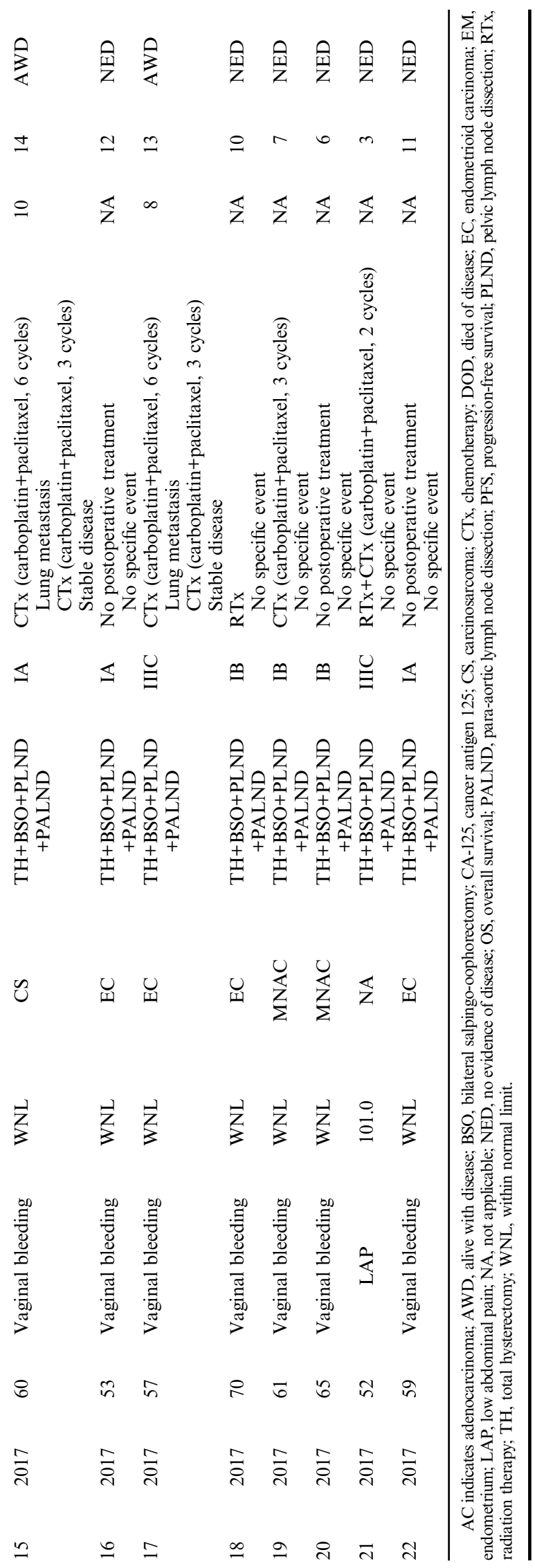

packages/pindel/), respectively. ANNOVAR (http://annovar. openbioinformatics.org/) was used to annotate the detected variants. Any SNV present at $>0.1 \%$ in Exome Variant Server (https://evs.gs.washington.edu/) or dbSNP was filtered. The variants present in the Catalogue of Somatic Mutations in Cancer (http://evs.gs.washington.edu/EVS/) were reviewed. Copy number variation (CNV) $\log _{2}$ ratios were generated using a depth of coverage normalized against the median from a panel of normal uterine tissues.

\section{Literature Review}

The Medline database was thoroughly searched using the PubMed retrieval service (www.ncbi.nlm.nih. gov/pubmed/). The key words used were "mesonephric adenocarcinoma," "mesonephric carcinoma," "endometrium," "uterine corpus," and "uterine body."

\section{Statistical Analysis}

The $\chi^{2}$ test or Fisher exact test was used to examine whether the pathologic characteristics are associated with the development of metastasis. Multivariate logistic regression with a backward stepwise elimination method was used to identify independent predictors of metastatic disease. Statistical analyses were carried out using PASW Statistics for Windows (version 18.0; IBM, Armonk, NY). Statistical significance was defined as a $P$-value $<0.05$.

\section{RESULTS}

\section{Clinical Characteristics of UB-MNAC}

We identified 11 cases of UB-MNAC in our institutional pathology database and 11 reported cases through a thorough literature search. Table 1 summarizes the clinical characteristics. Of our 11 patients (cases 12 to 22), 10 patients had presented with vaginal bleeding. Patient age ranged from 52 to 70 years (median, 59y). All patients were postmenopausal women. Two patients showed increased serum CA-125 at initial diagnosis. Endometrial curettage was carried out in 8/11 patients. In these patients, histopathologic diagnoses were endometrioid carcinoma (5/8), MNAC (2/8), and carcinosarcoma (1/8). All patients underwent total hysterectomy and bilateral salpingo-oophorectomy with or without pelvic or para-aortic lymph node dissection.

The FIGO stage was IA in $3 / 11$, IB in $3 / 11$, III in $4 / 11$, and IV in $1 / 11$ patients. Metastasis was detected in $6 / 11$ patients, either initially (2/6) or during the follow-up period (4/6). The metastatic sites were lungs (4/6), regional lymph nodes (1/6), and lungs and regional lymph nodes (1/6). Four of the 5 patients with a FIGO stages III to IV tumor received carboplatin/paclitaxel-based chemoradiation therapy, and the remaining patient received carboplatin/paclitaxel-based chemotherapy. However, $4 / 5$ patients who received chemoradiation therapy (3/4) or chemotherapy (1/4) experienced disease progression. Three patients with FIGO stage I tumor did not receive any additional therapy, whereas the remaining $3 / 6$ patients received postoperative radiation therapy (1/6) or carboplatin/paclitaxel-based chemotherapy (2/6). One patient 
who received chemotherapy developed metastatic disease after surgery.

Overall, 5/11 patients experienced disease progression after surgery. Progression-free survival ranged from 8 to 50 months (median, $10 \mathrm{mo}$ ). Elevated serum CA-125 accompanied disease progression in $1 / 5$ patients. Four of the 5 patients with progressive disease received carboplatin/ paclitaxel-based chemotherapy, and the remaining patient was treated with combination chemotherapy with cisplatin, doxorubicin, and cyclophosphamide. These patients showed stable disease for 4 to 11 months (median, $7 \mathrm{mo}$ ) after the chemotherapy had begun. The remaining 6/11 patients showed no evidence of tumor recurrence during the follow-up period (range, 3 to $12 \mathrm{mo}$; median, $8.5 \mathrm{mo}$ ). All patients are currently alive.

\section{Pathologic Characteristics of UB-MNAC}

Table 2 summarizes the pathologic characteristics of UB-MNAC. The largest tumors were 1.5 to $7.4 \mathrm{~cm}$ (median, $3.7 \mathrm{~cm}$ ). Grossly, they presented as single, solid, or solid and cystic masses and were typically located in the lateral or posterior wall of the UB. Four of the 11 tumors protruded into the endometrial cavity, with exophytic or polypoid appearance. The surfaces of the protruded portions were either ulcerated (2/4) or smooth (2/4). Five tumors with an ill-defined border infiltrated deeply into the uterine wall, whereas the remaining 6/11 tumors had a well-defined border. The cut tumor surface was gray or yellow-to-tan (Fig. 1). Seven tumors contained a variable amount of coagulative necrosis and hemorrhage. Small uterine leiomyomata (3/11) and ovarian hemorrhagic cysts $(2 / 11)$ were also noted.

Histopathologically, the tumors exhibited diverse architectural patterns, with various combinations of tubular, glandular, papillary, retiform, glomeruloid, sex cord-like, and comedonecrosis-like patterns. These patterns frequently merged into each other. Tubular and glandular patterns were predominant in all cases. The tubules were small, round, uniform, and closely packed, and accompanied by little intervening stroma, producing a back-to-back appearance. They were lined by a single layer of cuboidal or flattened epithelial cells and sometimes possessed intraluminal hyaline-like eosinophilic material (Fig. 2A). The glandular pattern closely resembled that of endometrioid carcinoma (Fig. 2B). These glands varied in size and often exhibited intraluminal villous projections, which were lined by several layers of columnar epithelial cells. Some glands were cystically dilated (Fig. 2C). There were irregularshaped glandular lumina containing papillary cellular buds. Intraluminal floating papillary tufts and micropapillae were morphologically similar to those of serous carcinoma (Fig. 2D). The budding papillae were lined by a single layer of 10 to 20 cuboidal epithelial cells and contained fibrous or fibrovascular cores. Discohesive tumor cells within dilated glandular lumina were also observed. In $8 / 11$ cases, there were round-to-ovoid glands showing complex cribriform architectures within the lumina. These cribriform structures with a single point or 2 points of attachment to the outer glandular epithelium and the nonadherent portion producing crescent-like empty spaces mimicked a renal glomerulus (glomeruloid pattern; Fig. 2E). We found $2 / 11$ cases showing abundant necrotic debris, which filled the dilated glandular lumina and were surrounded by viable tumor cells arranged in a papillary, cribriform, or solid pattern. These morphologic features resembled comedonecrosis observed in situ in ductal carcinoma of the breast (comedonecrosis-like pattern; Fig. 2F). The retiform pattern was a relatively minor component, but was, at least focally, present in all cases. It was characterized by elongated, slit-like branching tubules and intraluminal papillary projections with hyalinized fibrous cores. The papillae were lined by a single or several layers of cuboidal or columnar epithelial cells. The slit-like tubules were surrounded by a reactive fibrous stroma (Fig. 2G). The sex cord-like pattern, which was observed in 2/11 cases, consisted of branching cords and trabeculae of tumor cells. The cords and trabeculae were separated by acellular, myxoid, or edematous stroma containing small, arborizing blood vessels (Fig. $2 \mathrm{H}$ ).

Cytopathologically, most tumor cells in all the patterns had vesicular and angulated nuclei, and contained scant, pale-to-eosinophilic cytoplasm. They lacked a hobnail appearance, prominent cytoplasmic clearing, and squamous or mucinous differentiation. The degree of nuclear atypia was assessed based on nuclear pleomorphism, coarse chromatin, and the presence of macronucleoli. Seven tumors exhibited mild-to-moderate nuclear atypia, and the remaining 4/11 tumors displayed severe nuclear atypia. Mitotic counts ranged from 4 to 23/10 high-power fields (median, 15/10 high-power fields; Fig. 3A) and were most numerous in the glandular pattern. Seven cases showed areas of coagulative tumor cell necrosis (Fig. 3B).

Among our 11 cases of UB-MNAC, 4 exhibited the sarcomatous component, which consisted of solid sheets of closely packed, oval-to-spindle cells and resembled nonspecific spindle cell sarcoma (Fig. 3C). In 3/4 cases, the tubules and glands partly merged with areas of the sarcomatous component. The sarcomatous component accounted for $\sim 10 \%$ to $20 \%$ the tumor. One of these 3 cases displayed a heterologous component in the form of chondrosarcomatous differentiation. The remaining of the 4 cases exhibited diffuse sheets of uniform, round-to-oval cells with scant cytoplasm that resembled those of lowgrade endometrial stromal sarcoma. Nuclear atypia was mild-to-moderate in 3/4 cases and severe in 1/4 case (Fig. 3D). Mitotic counts in the sarcomatous component ranged from 8 to $15 / 10$ high-power fields.

Histopathologic analysis of tumor topography revealed that the endomyometrium was involved in all cases, except 1. Parametrial extension was identified in $4 / 11$ cases; all of these tumors had an ill-defined border. Peritumoral stroma in both of pushing borders and infiltrative borders was scanty cellular and desmoplastic. Seven cases had frequent lymphovascular tumor cell emboli (Fig. 3E). Histopathologic examination results of metastatic tumor tissues were available for 3 cases. The metastatic tumors exhibited carcinomatous component of glandular pattern only (Fig. 3F). In all cases, neither mesonephric remnant 


\begin{tabular}{|c|c|c|c|c|c|c|c|c|c|c|c|c|c|c|c|c|}
\hline \multirow[b]{3}{*}{ Case } & \multirow{2}{*}{\multicolumn{2}{|c|}{ Gross Finding }} & \multicolumn{14}{|c|}{ Histopathologic Finding } \\
\hline & & & \multicolumn{7}{|c|}{ Architecture } & \multirow[b]{2}{*}{$\begin{array}{c}\text { Sarcomatous } \\
\text { Component }\end{array}$} & \multirow[b]{2}{*}{$\begin{array}{c}\text { Invasion } \\
\text { Depth }\end{array}$} & \multirow[b]{2}{*}{$\begin{array}{l}\text { FIGO } \\
\text { Stage }\end{array}$} & \multirow[b]{2}{*}{$\begin{array}{c}\text { Nuclear } \\
\text { Atypia }\end{array}$} & \multirow[b]{2}{*}{ CTCN } & \multirow[b]{2}{*}{ Mitosis } & \multirow[b]{2}{*}{ LVI } \\
\hline & $\begin{array}{c}\text { Tumor } \\
\text { Size } \\
(\mathrm{cm}) \\
\end{array}$ & $\begin{array}{l}\text { Tumor } \\
\text { Border }\end{array}$ & Tubular & Glandular & Papillary & Retiform & Glomeruloid & $\begin{array}{c}\text { Sex } \\
\text { Cord- } \\
\text { like }\end{array}$ & $\begin{array}{c}\text { Comedonecrosis- } \\
\text { like }\end{array}$ & & & & & & & \\
\hline 1 & 14.0 & Ill- & Present & Present & Present & Absent & Absent & Present & NA & $\begin{array}{c}\text { Present } \\
\text { (spindle cell) }\end{array}$ & $\begin{array}{l}\text { SM to } \\
\text { DM }\end{array}$ & IB & Severe & Present & Frequent & Present \\
\hline 2 & 8.0 & $\begin{array}{l}\text { Well- } \\
\text { defined }\end{array}$ & Present & Present & Absent & Present & Absent & Absent & NA & $\begin{array}{l}\text { Present } \\
\text { (spindle cell) }\end{array}$ & $\begin{array}{l}\text { SM to } \\
\text { DM }\end{array}$ & IB & Moderate & Present & $\begin{array}{l}\text { Up to } 3 / \\
\text { HPF }\end{array}$ & NA \\
\hline 3 & 8.0 & $\begin{array}{c}\text { Ill- } \\
\text { defined }\end{array}$ & Present & Present & Absent & Present & Absent & Absent & NA & Present & $\begin{array}{l}\text { SM to } \\
\text { DM }\end{array}$ & IB & NA & NA & NA & NA \\
\hline 4 & 3.5 & $\begin{array}{l}\text { Well- } \\
\text { defined }\end{array}$ & Present & Present & Absent & Present & Absent & Absent & NA & $\begin{array}{l}\text { Present } \\
\text { (ESS-like) }\end{array}$ & $\begin{array}{l}\text { EM to } \\
\text { DM }\end{array}$ & IB & $\begin{array}{l}\text { Mild to } \\
\text { moderate }\end{array}$ & NA & $\begin{array}{l}2 / 10 \\
\text { HPFs }\end{array}$ & Absent \\
\hline 5 & 3.7 & $\begin{array}{l}\text { Well- } \\
\text { defined }\end{array}$ & Present & Present & Present & Absent & Absent & Absent & NA & Absent & $\begin{array}{l}\text { EM to } \\
\text { DM }\end{array}$ & IB & NA & NA & NA & NA \\
\hline 6 & 8.0 & $\begin{array}{l}\text { Well- } \\
\text { defined }\end{array}$ & Present & Present & Present & Present & Present & Absent & NA & Absent & $\begin{array}{l}\text { EM to } \\
\text { DM }\end{array}$ & IVB & Mild & Present & $\begin{array}{l}27 / 10 \\
\text { HPFs }\end{array}$ & Present \\
\hline 7 & 3.5 & $\begin{array}{l}\text { Well- } \\
\text { defined }\end{array}$ & Present & Present & Absent & Present & Present & Present & NA & $\begin{array}{c}\text { Present } \\
\text { (spindle cell) }\end{array}$ & $\begin{array}{l}\text { SM to } \\
\text { DM }\end{array}$ & IB & NA & NA & NA & NA \\
\hline 8 & 8.0 & $\begin{array}{l}\text { Well- } \\
\text { defined }\end{array}$ & Present & Present & Absent & Present & Present & Present & NA & $\begin{array}{l}\text { Present } \\
\text { (spindle cell) }\end{array}$ & $\begin{array}{l}\text { EM to } \\
\text { DM }\end{array}$ & IB & NA & NA & NA & NA \\
\hline 9 & 2.7 & $\begin{array}{l}\text { Well- } \\
\text { defined }\end{array}$ & Present & Present & Present & Present & Present & Absent & NA & Absent & $\begin{array}{l}\text { EM to } \\
\text { DM }\end{array}$ & IB & $\begin{array}{l}\text { Mild to } \\
\text { moderate }\end{array}$ & Absent & $\begin{array}{l}10 / 10 \\
\text { HPFs }\end{array}$ & NA \\
\hline 10 & 3.5 & NA & NA & NA & NA & NA & NA & NA & NA & Present & $\begin{array}{l}\text { SM to } \\
\text { DM }\end{array}$ & II & NA & NA & NA & Absent \\
\hline 11 & 5.8 & NA & NA & NA & NA & NA & NA & NA & NA & Present & $\begin{array}{l}\text { EM to } \\
\text { DM }\end{array}$ & IIIC & NA & NA & NA & Absent \\
\hline 12 & 2.3 & $\begin{array}{c}\text { Ill- } \\
\text { defined }\end{array}$ & Present & Present & Present & Present & Absent & Absent & Absent & Absent & $\begin{array}{l}\text { EM to } \\
\text { PM }\end{array}$ & IIIB & $\begin{array}{l}\text { Mild to } \\
\text { moderate }\end{array}$ & Present & $\begin{array}{l}15 / 10 \\
\text { HPFs }\end{array}$ & Present \\
\hline 13 & 7.4 & $\begin{array}{l}\text { Well- } \\
\text { defined }\end{array}$ & Present & Present & Present & Present & Present & Absent & Absent & Absent & $\begin{array}{l}\text { EM to } \\
\text { DM }\end{array}$ & IVB & $\begin{array}{l}\text { Mild to } \\
\text { moderate }\end{array}$ & Present & $\begin{array}{l}23 / 10 \\
\text { HPFs }\end{array}$ & Present \\
\hline 14 & 4.3 & $\begin{array}{c}\text { Ill- } \\
\text { defined }\end{array}$ & Present & Present & Present & Present & Present & Present & Present & $\begin{array}{c}\text { Present } \\
\text { (spindle cell) }\end{array}$ & $\begin{array}{l}\text { EM to } \\
\text { PM }\end{array}$ & IIIB & Severe & Present & $\begin{array}{l}19 / 10 \\
\text { HPFs }\end{array}$ & Present \\
\hline 15 & 4.1 & $\begin{array}{c}\text { Ill- } \\
\text { defined }\end{array}$ & Present & Present & Present & Present & Present & Absent & Absent & $\begin{array}{c}\text { Present } \\
\text { (spindle cell) }\end{array}$ & $\begin{array}{l}\text { EM to } \\
\text { SM }\end{array}$ & IA & Severe & Present & $\begin{array}{l}21 / 10 \\
\text { HPFs }\end{array}$ & Present \\
\hline 16 & 2.3 & $\begin{array}{l}\text { Well- } \\
\text { defined }\end{array}$ & Present & Present & Present & Present & Present & Present & Absent & $\begin{array}{l}\text { Present } \\
\text { (ESS-like) }\end{array}$ & $\begin{array}{l}\text { EM to } \\
\text { SM }\end{array}$ & IA & $\begin{array}{l}\text { Mild to } \\
\text { moderate }\end{array}$ & Absent & $\begin{array}{l}4 / 10 \\
\text { HPFs }\end{array}$ & Absent \\
\hline 17 & 5.7 & $\begin{array}{c}\text { Ill- } \\
\text { defined }\end{array}$ & Present & Present & Present & Present & Present & Absent & Present & Absent & $\begin{array}{l}\text { SM to } \\
\text { PM }\end{array}$ & IIIC & Severe & Present & $\begin{array}{l}19 / 10 \\
\text { HPFs }\end{array}$ & Present \\
\hline 18 & 2.6 & $\begin{array}{l}\text { Well- } \\
\text { defined }\end{array}$ & Present & Present & Present & Present & Present & Present & Absent & Absent & $\begin{array}{l}\text { EM to } \\
\text { DM }\end{array}$ & IB & $\begin{array}{l}\text { Mild to } \\
\text { moderate }\end{array}$ & Absent & $\begin{array}{l}8 / 10 \\
\text { HPFs }\end{array}$ & Absent \\
\hline 19 & 2.2 & $\begin{array}{l}\text { Well- } \\
\text { defined }\end{array}$ & Present & Present & Present & Present & Present & Present & Absent & Absent & $\begin{array}{l}\text { EM to } \\
\text { DM }\end{array}$ & IB & $\begin{array}{l}\text { Mild to } \\
\text { moderate }\end{array}$ & Absent & $\begin{array}{l}7 / 10 \\
\text { HPFs }\end{array}$ & Present \\
\hline 20 & 3.7 & $\begin{array}{l}\text { Well- } \\
\text { defined }\end{array}$ & Present & Present & Present & Present & Absent & Absent & Absent & Absent & $\begin{array}{l}\text { EM to } \\
\text { DM }\end{array}$ & IB & Severe & Present & $\begin{array}{c}5 / 10 \\
\text { HPFs }\end{array}$ & Absent \\
\hline 21 & 4.8 & $\begin{array}{c}\text { Ill- } \\
\text { defined }\end{array}$ & Present & Present & Present & Present & Absent & Absent & Absent & $\begin{array}{c}\text { Present } \\
\text { (spindle cell) }\end{array}$ & $\begin{array}{l}\text { EM to } \\
\text { PM }\end{array}$ & IIIC & $\begin{array}{l}\text { Mild to } \\
\text { moderate }\end{array}$ & Present & $\begin{array}{l}17 / 10 \\
\text { HPFs }\end{array}$ & Present \\
\hline 22 & 1.5 & $\begin{array}{l}\text { Well- } \\
\text { defined }\end{array}$ & Present & Present & Present & Present & Absent & Absent & Absent & Absent & $\begin{array}{l}\text { EM to } \\
\text { SM }\end{array}$ & IA & $\begin{array}{l}\text { Mild to } \\
\text { moderate }\end{array}$ & Absent & $\begin{array}{l}6 / 10 \\
\text { HPFs }\end{array}$ & Absent \\
\hline
\end{tabular}



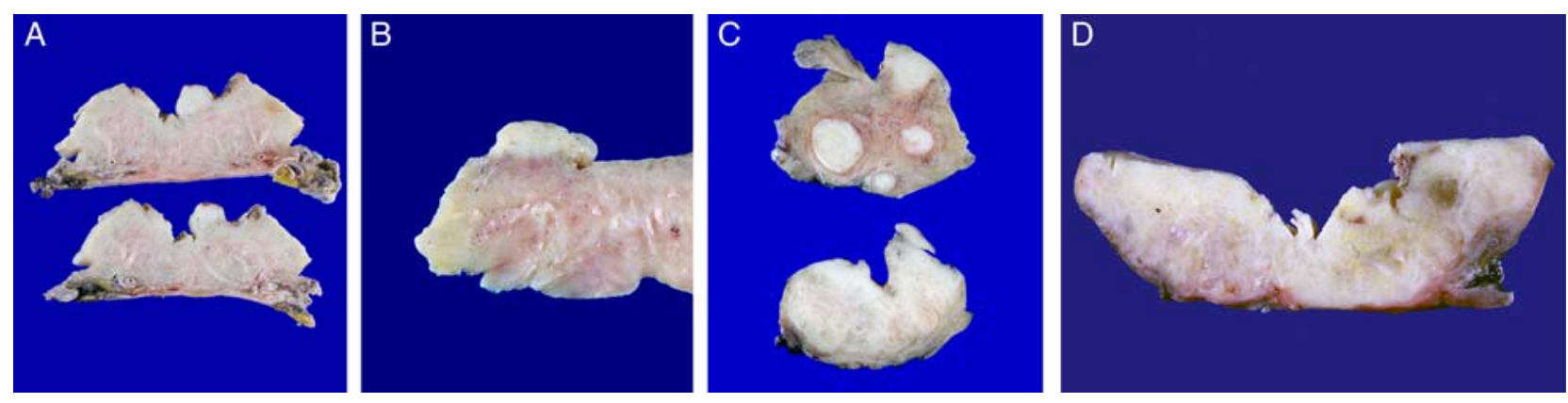

FIGURE 1. Gross findings of UB-MNAC. A and B, The tumor protrudes into the endometrial cavity, without grossly definite myometrial invasion. C, The tumor deeply infiltrates into the myometrium (lower panel). The cut surface of the tumor closely resembles that of intramural leiomyoma (upper panel). D, The tumor infiltrates the entire uterine wall.

nor mesonephric hyperplasia was identified in the adjacent myometrium. The following coexistent gynecologic lesions were identified: adenomyosis (6/11), leiomyoma (3/11), and ovarian endometriosis (2/11).

\section{Association Between Metastasis and Pathologic Characteristics of UB-MNAC}

We further examined whether the above-mentioned pathologic characteristics are associated with the development of metastasis. Six characteristics, including large tumor size $(>4 \mathrm{~cm})$, ill-defined tumor border, advanced FIGO stages (III to IV), presence of coagulative tumor cell necrosis, high mitotic activity ( $>10 / 10$ high-power fields), and presence of lymphovascular invasion, were significantly associated with the development of metastasis (Table 3). In multivariate analysis, advanced FIGO stage, high mitotic activity, and lymphovascular invasion were found to be independent factors predicting the development of metastasis (Table 3). The remaining features, including architectural pattern, extrauterine extension, deep invasion, severe nuclear atypia, and presence of sarcomatous component, were not significantly associated with metastasis. Six patients who developed metastasis had 4 or more of adverse characteristics in various combinations (range, 4 to 6 ), whereas $<3$ of adverse characteristics (range, 0 to 2 ) were found in 5 patients without metastasis.

\section{Immunophenotype of UB-MNAC}

Table 4 summarizes the results of immunohistochemical staining. All (11/11) cases were positive for GATA3 (Fig. 4A), although both the extent and intensity of GATA3 positivity varied. Eight cases showed diffuse GATA3 immunoreactivity with moderate to strong intensity, whereas the remaining $3 / 11$ cases displayed focal GATA3 expression, also with variable intensity. Areas showing sarcomatous component, as evidenced by spindled growth, present in 4 cases were consistently negative for GATA3 in contrast to more welldifferentiated areas of these tumors with tubular or papillary architecture. All (11/11) cases examined displayed diffuse PAX2 immunoreactivity (Fig. 4B). In contrast to the weak-tomoderate staining intensity of PAX2 in non-neoplastic endometrial glandular epithelium, staining intensity in the tumor cells was uniformly strong in all cases examined. PTEN expression was preserved in all cases examined (11/11; Fig. 4C). ER (0/11; Fig. 4D) and PR (0/11; Fig. 4E) expression was negative in all cases examined. The tumor cells exhibited wild-type p53 immunostaining pattern (Fig. 4F) and negative (patchy) p16 immunoreactivity in both the nuclei and the cytoplasm (Fig. 4G). CD10 immunostaining revealed a luminal expression pattern in 11/11 cases (Fig. $4 \mathrm{H})$. Calretinin expression was focally positive in $3 / 11$ cases (Fig. 4I). The tumor cells demonstrated diffuse and strong membranous cytokeratin 7 immunoreactivity.

\section{Genetic Alterations Associated With UB-MNAC}

The 12 tumor-tissue samples subjected to NGS consisted of 11 primary UB-MNACs and 1 metastatic UB-MNAC. The average number of unique, high-quality, aligned reads was $8,592,849$ (range, 5,458,235 to 12,852,702), with an average target coverage of $1969 \times$ (range, 787 to $3211 \times$ ). Overall, $98.87 \%$ of the targeted sequences had at least $30 \times$ target base coverage across the samples.

Forty-two SNVs were identified in 16 genes and consisted of 36 missense mutations, 3 frameshift mutations, and 3 nonsense mutations (Fig. 5). Twenty-two of these 42 SNVs had been previously reported as somatic mutations in other tumors. The most commonly detected SNV in UB-MNAC was activating $K R A S$ mutation (10/12), including G12V (6/12), G12C (2/12), and G12D (2/12). The second most common SNV was ARIDIA mutation (9/12), including T294P (6/12), Q288P (2/12), and Q287Pfs (1/12). Recurrent somatic mutation of $P T C H 2$ was identified in $4 / 12$ cases.

$\mathrm{CNV}$ was found in 16 genomic regions and included 57 gains and 10 losses (Fig. 6). Most of the CNVs were arm-level alterations involving $>2$ genes. CNV involving a single gene was detected in 6 regions $(2 \mathrm{q}$ gain, $3 \mathrm{q}$ loss, $5 \mathrm{p}$ gain, 6q gain, 16q gain, and 19p gain). Eleven cases had gain of $1 \mathrm{q}$, and 2 of the cases with 1q gain also had loss of $1 \mathrm{p}$. Other recurrent CNVs included $9 \mathrm{p}$ gain $(7 / 12), 20 \mathrm{q}$ gain $(7 / 12), 12 q$ gain $(6 / 12), 6 q$ gain $(4 / 12), 10 q$ gain $(4 / 12)$, $3 q$ loss $(3 / 12)$, $5 p$ gain $(3 / 12)$, $7 q$ gain $(3 / 12), 19 p$ gain $(3 / 12)$, and gain of chromosome $2(3 / 12)$. Gain of $10 \mathrm{q}$ was detected exclusively in 3 cases with metastasis.

Of note, primary (case 13A) and metastatic (case 13B) tumors exhibited identical mutations in KRAS and $A R I-$ $D 1 A$ and shared the same CNV pattern. Additional PTEN 

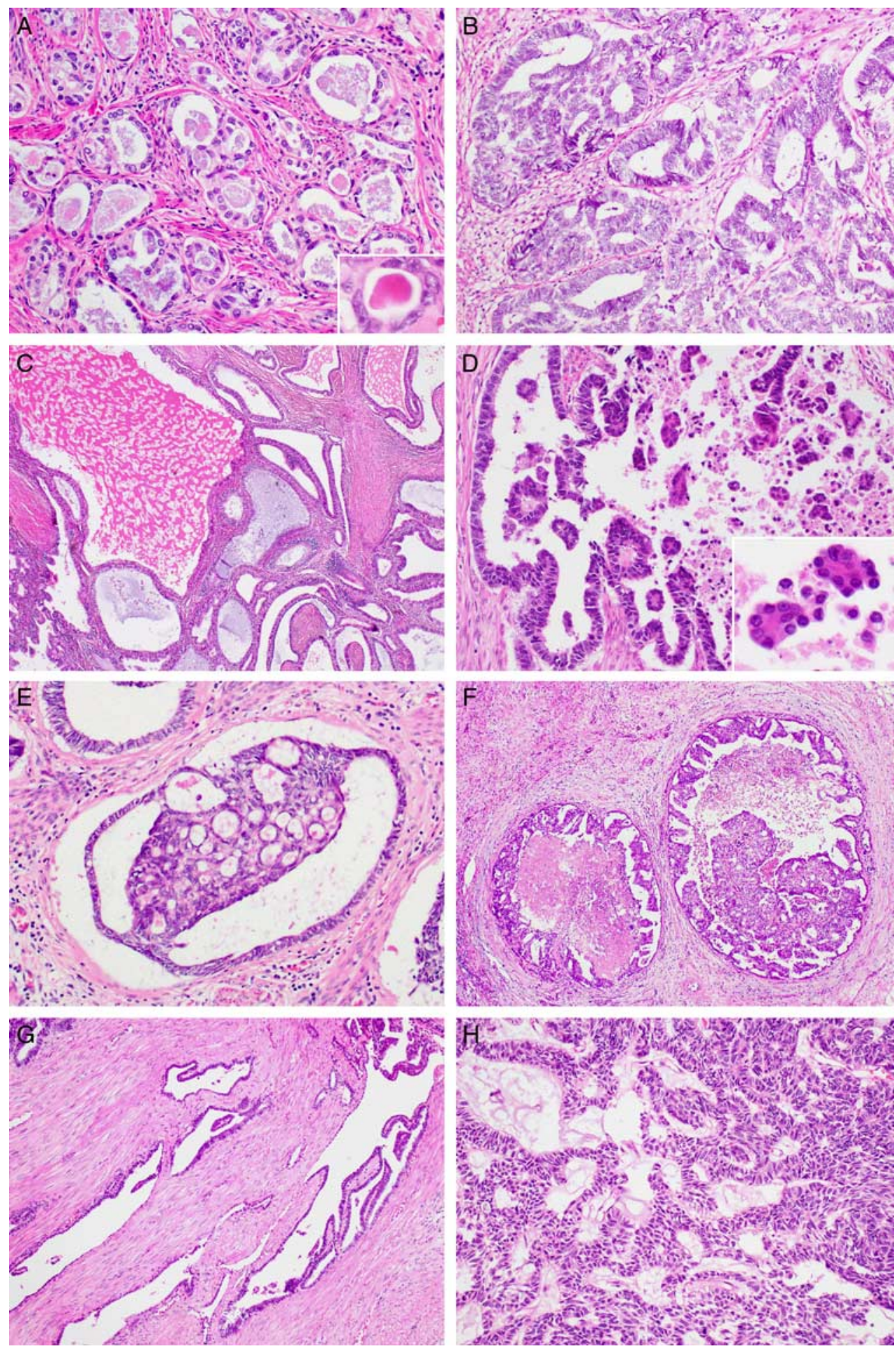

FIGURE 2. Histopathologic findings of UB-MNAC: architectural patterns. A, Tubular pattern. The tubules are lined by a single layer of cuboidal cells and possess intraluminal eosinophilic material (inset). B, Glandular pattern. The endometrioid-like glands are lined by several layers of columnar epithelium. C, Glandular pattern. Some glands are cystically dilated and irregular in shape. D, Papillary pattern. Note the intraluminal papillary projections and floating micropapillary tufts (inset). E, Glomeruloid pattern. Dilated glands contain intraluminal cribriform structures with 2 points of attachment, resembling a renal glomerulus. F, Comedonecrosis-like pattern showing necrotic debris centrally located in the dilated glandular lumina and surrounded by tumor cells arranged in a papillary, cribriform, or solid pattern. G, Retiform pattern showing elongated, slit-like branching tubules. H, Sex cord-like pattern showing anastomosing trabeculae and cords of tumor cells with background of edematous or myxoid stroma. 

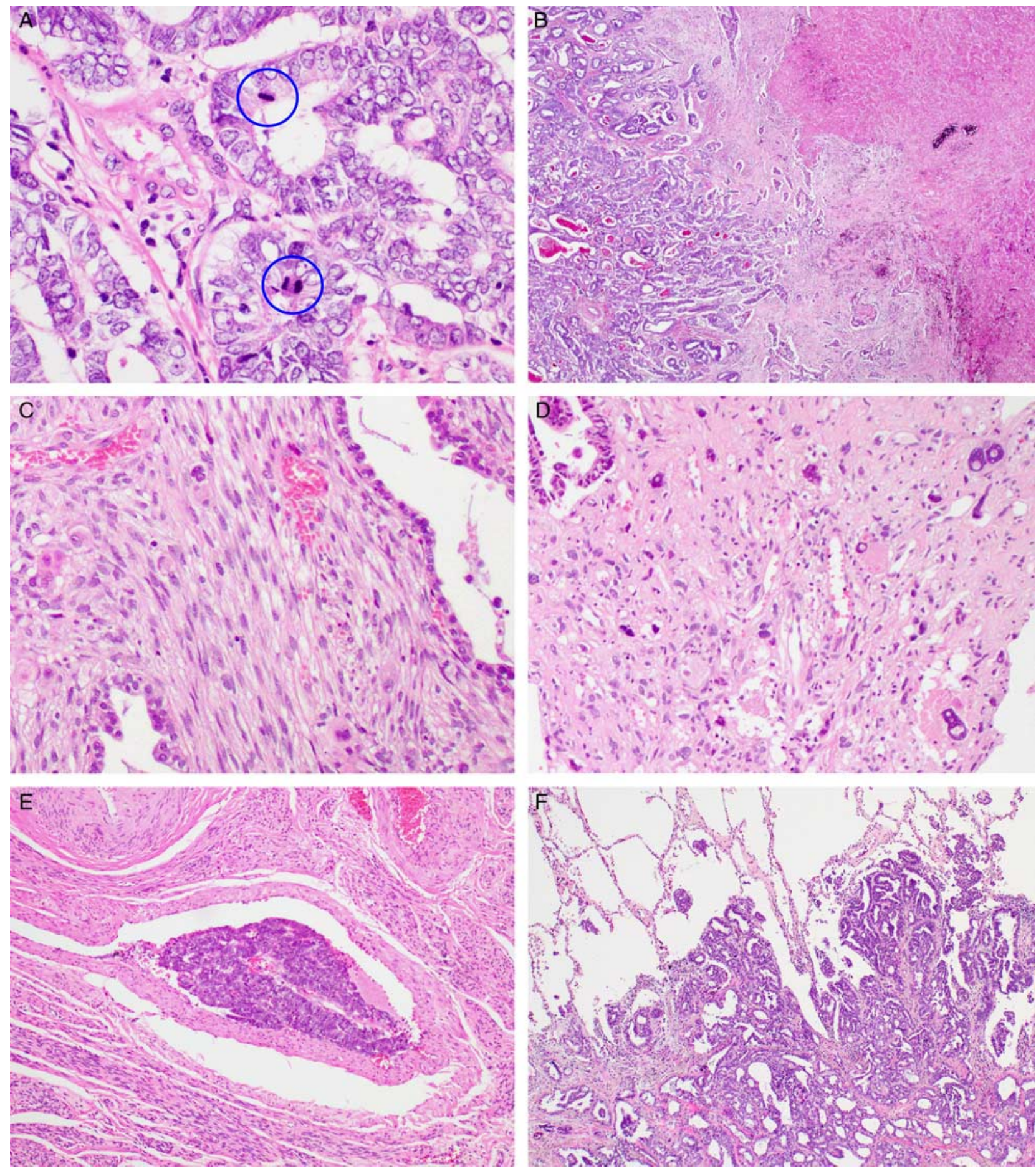

FIGURE 3. Histopathologic findings of UB-MNAC: adverse pathologic characteristics and metastasis. A, High mitotic activity. Blue circles indicate mitotic figures. B, Coagulative tumor cell necrosis. C, Sarcomatous component resembling nonspecific spindle cell sarcoma. D, Sarcomatous component showing severe nuclear pleomorphism. Note large, bizarre nuclei with intranuclear vacuoles (right upper and lower corners). E, Lymphovascular invasion. F, Histopathologic examination of pulmonary metastatic lesion reveals the carcinomatous component in the glandular pattern only.

mutation (D268E) was detected in metastatic tumor only, indicating that PTEN mutation is a relatively late event in the sequence of genetic alterations in UB-MNAC.

\section{DISCUSSION}

This study aimed to comprehensively analyze the clinicopathologic characteristics of and molecular genetic 
TABLE 3. Association Between Metastasis and Pathologic Characteristics of UB-MNAC

\begin{tabular}{|c|c|c|c|c|}
\hline \multirow[b]{3}{*}{ Characteristics } & \multicolumn{3}{|c|}{ Univariate } & \multirow{3}{*}{$\begin{array}{c}\text { Multivariate } \\
P \\
\end{array}$} \\
\hline & \multicolumn{2}{|c|}{ Metastasis } & \multirow[b]{2}{*}{$\boldsymbol{P}$} & \\
\hline & Present & Absent & & \\
\hline \multicolumn{5}{|l|}{ Tumor size } \\
\hline$>4 \mathrm{~cm}$ & $5(100.0)$ & 0 & $0.015^{*}$ & 0.102 \\
\hline$\leq 4 \mathrm{~cm}$ & $1(16.7)$ & $5(83.3)$ & & \\
\hline \multicolumn{5}{|l|}{ Tumor border } \\
\hline Ill-defined & $5(100.0)$ & 0 & $0.015^{*}$ & 0.102 \\
\hline Well-defined & $1(16.7)$ & $5(83.3)$ & & \\
\hline \multicolumn{5}{|l|}{ Architecture } \\
\hline \multicolumn{5}{|l|}{ Tubular } \\
\hline Present & $6(54.5)$ & $5(45.5)$ & - & - \\
\hline Absent & 0 & 0 & & \\
\hline \multicolumn{5}{|l|}{ Glandular } \\
\hline Present & $6(54.5)$ & $5(45.5)$ & - & - \\
\hline Absent & 0 & 0 & & \\
\hline \multicolumn{5}{|l|}{ Papillary } \\
\hline Present & $6(54.5)$ & $5(45.5)$ & - & - \\
\hline Absent & 0 & 0 & & \\
\hline \multicolumn{5}{|l|}{ Retiform } \\
\hline Present & $6(54.5)$ & $5(45.5)$ & - & - \\
\hline Absent & 0 & 0 & & \\
\hline \multicolumn{5}{|l|}{ Glomeruloid } \\
\hline Present & $4(57.1)$ & $3(42.9)$ & 1.000 & - \\
\hline Absent & $2(50.0)$ & $2(50.0)$ & & \\
\hline \multicolumn{5}{|l|}{ Sex cord-like } \\
\hline Present & $1(25.0)$ & $3(75.0)$ & 0.242 & - \\
\hline Absent & $5(71.4)$ & $2(28.6)$ & & \\
\hline \multicolumn{5}{|c|}{ Comedonecrosis-like } \\
\hline Present & $2(100.0)$ & 0 & 0.455 & - \\
\hline Absent & $4(44.4)$ & $5(55.6)$ & & \\
\hline \multicolumn{5}{|c|}{ Sarcomatous component } \\
\hline Present & $3(75.0)$ & $1(25.0)$ & 0.545 & - \\
\hline Absent & $3(42.9)$ & $4(57.1)$ & & \\
\hline \multicolumn{5}{|l|}{ Extrauterine extension } \\
\hline Present & $4(100.0)$ & 0 & 0.061 & - \\
\hline Absent & $2(28.6)$ & $5(71.4)$ & & \\
\hline \multicolumn{5}{|l|}{ Invasion depth } \\
\hline EM-SM & $5(62.5)$ & $3(37.5)$ & 0.545 & - \\
\hline DM-PM & $1(33.3)$ & $2(66.7)$ & & \\
\hline \multicolumn{5}{|l|}{ FIGO stage } \\
\hline III-IV & $5(100.0)$ & 0 & $0.015^{*}$ & $0.046^{*}$ \\
\hline I-II & $1(16.7)$ & $5(83.3)$ & & \\
\hline Nuclear atypia & & & & \\
\hline Severe & $3(75.0)$ & $1(25.0)$ & 0.545 & - \\
\hline Mild to moderate & $3(42.9)$ & $4(57.1)$ & & \\
\hline Coagulative tumor c & hecrosis & & & \\
\hline Present & $6(85.7)$ & $1(14.3)$ & $0.015^{*}$ & 0.102 \\
\hline Absent & 0 & $4(100.0)$ & & \\
\hline Mitosis & & & & \\
\hline$>$ 10/10 HPFs & $6(100.0)$ & 0 & $0.002 *$ & $0.025^{*}$ \\
\hline$\leq 10 / 10 \mathrm{HPFs}$ & 0 & $5(100.0)$ & & \\
\hline Lymphovascular inva & & & & \\
\hline Present & $6(85.7)$ & $1(14.3)$ & $0.015^{*}$ & $0.046^{*}$ \\
\hline Absent & 0 & $4(100.0)$ & & \\
\hline
\end{tabular}

alterations associated with UB-MNAC. Eleven cases of UBMNAC have been reported to date (Table 1). ${ }^{10-18}$ At the time of diagnosis, the FIGO stage was IB in 8 , II in 1, III in 1, and IV in 1 patients. Six patients with FIGO stage I tumor received no additional therapy after surgery, whereas the remaining 2/8 patients received postoperative radiation therapy. Three patients with FIGO stage I tumor developed metastatic disease after surgery. Two patients with FIGO stages II to IV who received carboplatin/paclitaxel-based chemotherapy showed disease progression, and the other patient who received cisplatin/docetaxel-based chemoradiation therapy showed no evidence of disease. Overall, 4/11 patients experienced disease progression after surgery. Progression-free survival ranged from 4 to 10 months (median, $7 \mathrm{mo}$ ). The data of these previously reported cases are in agreement with our results in view of clinical presentation, age distribution, and disease progression rate. The most common presenting symptom was vaginal bleeding (7/11). Patient age ranged from 33 to 81 years (median, $58 \mathrm{y})$. Two $(25.0 \%)$ and $1(16.6 \%)$ of the 8 reported and 6 of our patients with FIGO stage I disease, respectively, experienced progressive disease. Similarly, progression in FIGO stages II to IV disease was observed in $2 / 3(66.6 \%)$ previously reported cases and $4 / 5(80 \%)$ of our cases.

Among our 11 cases and the reported 11 cases of UB-MNAC, half $(11 / 22)$ of the patients developed metastatic disease. We found that the metastatic rate of UB-MNAC (50.0\%) was substantially higher than that reported for UC-MNAC, which shows metastatic disease in $\sim 10 \%$ of the cases. ${ }^{8,9}$ UB-MNAC presented with more advanced FIGO stages (III to IV) than does UC-MNAC $(36.3 \% \text { vs. } 5 \%)^{8,9}$ Furthermore, disease progression in UB-MNAC patients mainly manifested as distant metastasis. Pulmonary metastasis is a very unusual event in endometrial carcinoma. ${ }^{26,27}$ However, in this study, UB-MNAC most commonly metastasized to the lungs. The reason for frequent pulmonary involvement of UB-MNAC is unclear, but our observation of vascular invasion in the peritumoral areas supports hematogenous spread as one of the possible mechanisms. Our findings warrant caution in the clinical surveillance and therapeutic strategies for UB-MNAC, considering its high metastatic potential and frequent pulmonary involvement.

The main differential diagnosis of UB-MNAC is endometrial endometrioid carcinoma, as UB-MNAC predominantly consists of tubular and glandular architectural patterns. Features in favor of UB-MNAC include lack of endometrial hyperplasia or endometrioid intraepithelial neoplasia in the background, absence of squamous differentiation and mucin, and identification of myometrialbased lesions. Positive immunoreactivity for GATA3 and PAX2 and negativity for hormone receptors ER and PR support the diagnosis of UB-MNAC, ${ }^{5,28}$ When a papillary architectural pattern in association with high-grade nuclear atypia is observed, endometrial serous carcinoma should be considered in the differential diagnosis. The presence of intraluminal eosinophilic colloid-like material, wild-type p53 immunostaining pattern, patchy p16 expression, and positive GATA3 expression are features supportive of UB-MNAC. ${ }^{29}$ The occurrence of admixtures of architectural patterns sometimes renders it difficult to differentiate UB-MNAC from endometrial clear cell carcinoma. Clear cell carcinoma typically exhibits wild-type p53 immunostaining pattern, patchy p16 expression, and negative staining for ER and PR ${ }^{30}$ However, the absence of hobnail cells, a prominent clear cell change, and eosinophilic stromal 


\begin{tabular}{|c|c|c|c|c|c|c|c|c|c|}
\hline GATA3 & PAX2 & PTEN & ER & PR & p53 & p16 & CD10 & Calretinin & CK7 \\
\hline NA & NA & NA & NA & NA & NA & NA & NA & NA & NA \\
\hline NA & NA & NA & Negative & Negative & Wild-type pattern & NA & Positive (luminal) & NA & Positive \\
\hline NA & NA & NA & NA & NA & NA & NA & Positive & Positive (focal) & NA \\
\hline NA & NA & NA & Negative & Negative & NA & NA & Negative & Positive & NA \\
\hline NA & NA & NA & Negative & Negative & Wild-type pattern & NA & Positive (luminal) & Positive (focal) & NA \\
\hline NA & NA & NA & Negative & Negative & NA & NA & Positive (luminal) & Positive & NA \\
\hline NA & NA & NA & Negative & Negative & NA & NA & Positive & Positive & NA \\
\hline NA & NA & NA & Negative & Negative & Wild-type pattern & NA & Positive & Negative & NA \\
\hline Positive & Positive & Positive & Negative & Negative & Wild-type pattern & Negative (patchy) & Positive (luminal) & Negative & Positive \\
\hline Positive & Positive & Positive & Negative & Negative & Wild-type pattern & Negative (patchy) & Positive (luminal) & Positive (focal) & Positive \\
\hline Positive (focal) & Positive & Positive & Negative & Negative & Wild-type pattern & Negative (patchy) & Positive (luminal) & Positive (focal) & Positive \\
\hline Positive (focal) & Positive & Positive & Negative & Negative & Wild-type pattern & Negative (patchy) & Positive (luminal) & Negative & Positive \\
\hline Positive & Positive & Positive & Negative & Negative & Wild-type pattern & Negative (patchy) & Positive (luminal) & Negative & Positive \\
\hline Positive & Positive & Positive & Negative & Negative & Wild-type pattern & Negative (patchy) & Positive (luminal) & Negative & Positive \\
\hline
\end{tabular}

CK7 indicates cytokeratin 7; NA, not applicable.
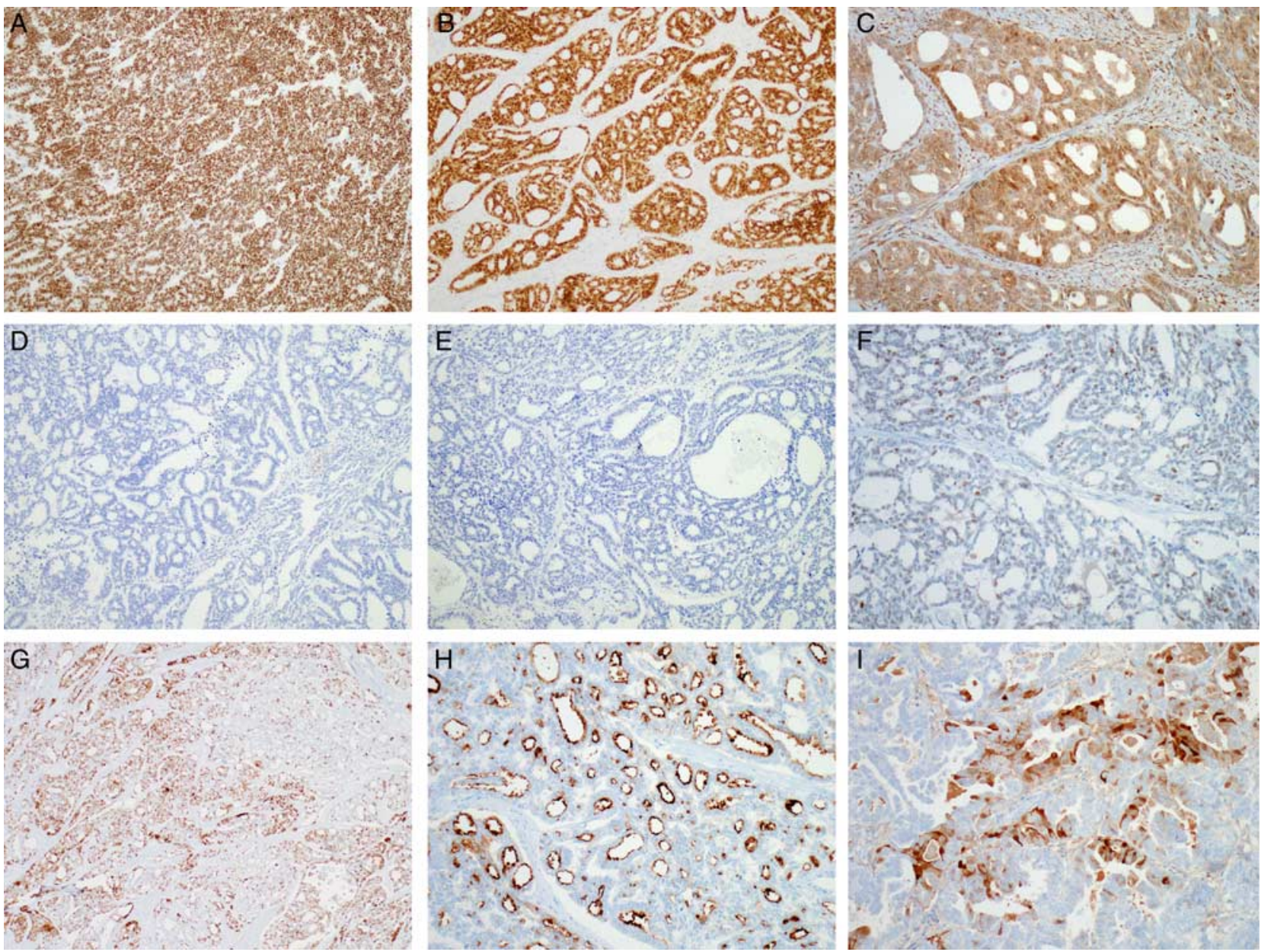

FIGURE 4. Immunostaining results of UB-MNAC. A, Uniform nuclear GATA3 expression. B, Diffuse and strong nuclear PAX2 immunoreactivity. C, Preserved PTEN expression. D, Lack of ER expression. E, Lack of PR expression. F, Wild-type p53 immunostaining pattern. G, Focal p16 expression. H, Uniform CD10 immunoreactivity along the luminal surface. I, Focal calretinin expression. 


\begin{tabular}{|c|c|c|c|c|c|c|c|c|c|c|c|c|c|}
\hline \multicolumn{2}{|c|}{ SNV } & \multicolumn{12}{|c|}{ Case } \\
\hline \multirow{17}{*}{ Gene } & & 12 & $13 \mathrm{~A}$ & $13 B$ & 14 & 15 & 16 & 17 & 18 & 19 & 20 & 21 & 22 \\
\hline & KRAS & & & & & & & & & & & & \\
\hline & $A R I D 1 A$ & & & & & & & & & & & & \\
\hline & $A K T 1$ & & & & & & & & & & & & \\
\hline & CSF1R & & & & & & & & & & & & \\
\hline & GNAQ & & & & & & & & & & & & \\
\hline & $\mathrm{NOTCH} 1$ & & & & & & & & & & & & \\
\hline & PTCH2 & & & & & & & & & & & & \\
\hline & PTEN & & & & & & & & & & & & \\
\hline & $A B L 1$ & & & & & & & & & & & & \\
\hline & EPHB4 & & & & & & & & & & & & \\
\hline & ATM & & & & & & & & & & & & \\
\hline & RET & & & & & & & & & & & & \\
\hline & $\mathrm{CDH} 1$ & & & & & & & & & & & & \\
\hline & $N F 1$ & & & & & & & & & & & & \\
\hline & MET & & & & & & & & & & & & \\
\hline & ATRX & & & & & & & & & & & & \\
\hline & & stas & & & $\begin{array}{l}\text { Misse } \\
\text { muta }\end{array}$ & & & $\begin{array}{l}\text { lons } \\
\text { muta }\end{array}$ & & & mut & & \\
\hline
\end{tabular}

FIGURE 5. Summary of SNVs identified in 12 UB-MNACs by NGS. Each column represents a case, and each row represents a gene.

hyalinization, in addition to positive immunoreactivity for GATA3 and PAX2, helps to exclude the possibility of clear cell carcinoma.

The diagnosis of UB-MNAC on the basis of endometrial curettage is complicated, as these specimens may include only part of the tumor tissue, showing only a single growth pattern. Upon review of 8 curettage specimens from our cohort, 3 cases displayed $>1$ architectural pattern, whereas 5 specimens had only the glandular pattern. In these cases, it was almost impossible to differentiate UB-MNAC from endometrioid carcinoma without additional immunohistochemical staining data. However, we doubt that immunostaining should be performed in all curettage specimens exhibiting malignant tumors with glandular differentiation to exclude the possibility of UB-MNAC. This is a cost-effect issue, as UB-MNAC is extremely rare.

We investigated the relationship between the development of metastasis and 11 pathologic characteristics of UBMNAC. Large tumor size, ill-defined tumor border, advanced FIGO stage, presence of coagulative tumor cell necrosis, high mitotic activity, and presence of lymphovascular invasion were significantly associated with the development of metastasis. In addition, in multivariate regression, advanced FIGO stage, high mitotic activity, and lymphovascular invasion were identified as independent factors predicting the development of metastasis. The statistical significance of analyses using 22 cases including 11 previously reported cases was consistent with that using our 11 cases (Supplementary Table 2, Supplementary Digital Content 1, http://links.lww.com/PAS/A567). These findings suggest that pathologic characteristics conventionally used for the prognostication of patients with endometrial carcinoma are also valuable in classifying patients with UB-MNAC into high-risk and low-risk groups for metastasis. A significant relationship between the presence of sarcomatous component and aggressive biological behavior has been suggested in UC-MNAC. ${ }^{9}$ However, this seemed not the case based on our cohort. In fact, our observation that metastatic tumor tissues consisted solely of carcinomatous component (exclusively of glandular pattern) attests against a relationship between the presence of sarcomatous component and metastasis. There is no standard grading system for nuclear atypia of MNAC. In this study, the degree of nuclear atypia determined based on the FIGO grading system for endometrioid carcinoma did not show a significant relationship with metastasis. It has been reported that MNAC nuclear features in most cases would be graded 2 to 3 by the FIGO grading system, but are not classic grade 3 nuclei. ${ }^{5}$ To our experience and that of other authors, the FIGO grading system may not appropriately reflect the severity of UB-MNAC.

The molecular pathogenesis and driver-mutation profile of MNAC remain largely unknown. In this study, analyses of NGS data revealed that 10/12 cases of UB-MNAC harbored activating KRAS mutation. This finding is consistent with previous observations by Mirkovic et $\mathrm{al}^{20}$ who reported activating $K R A S$ and $N R A S$ mutations in 12/17 and 1/17 cases of MNAC, respectively. Considering that the majority (12/17) of tumor samples in their report were of cervical origin, $K R A S$ mutation appears to be a driver mutation in MNAC of either 


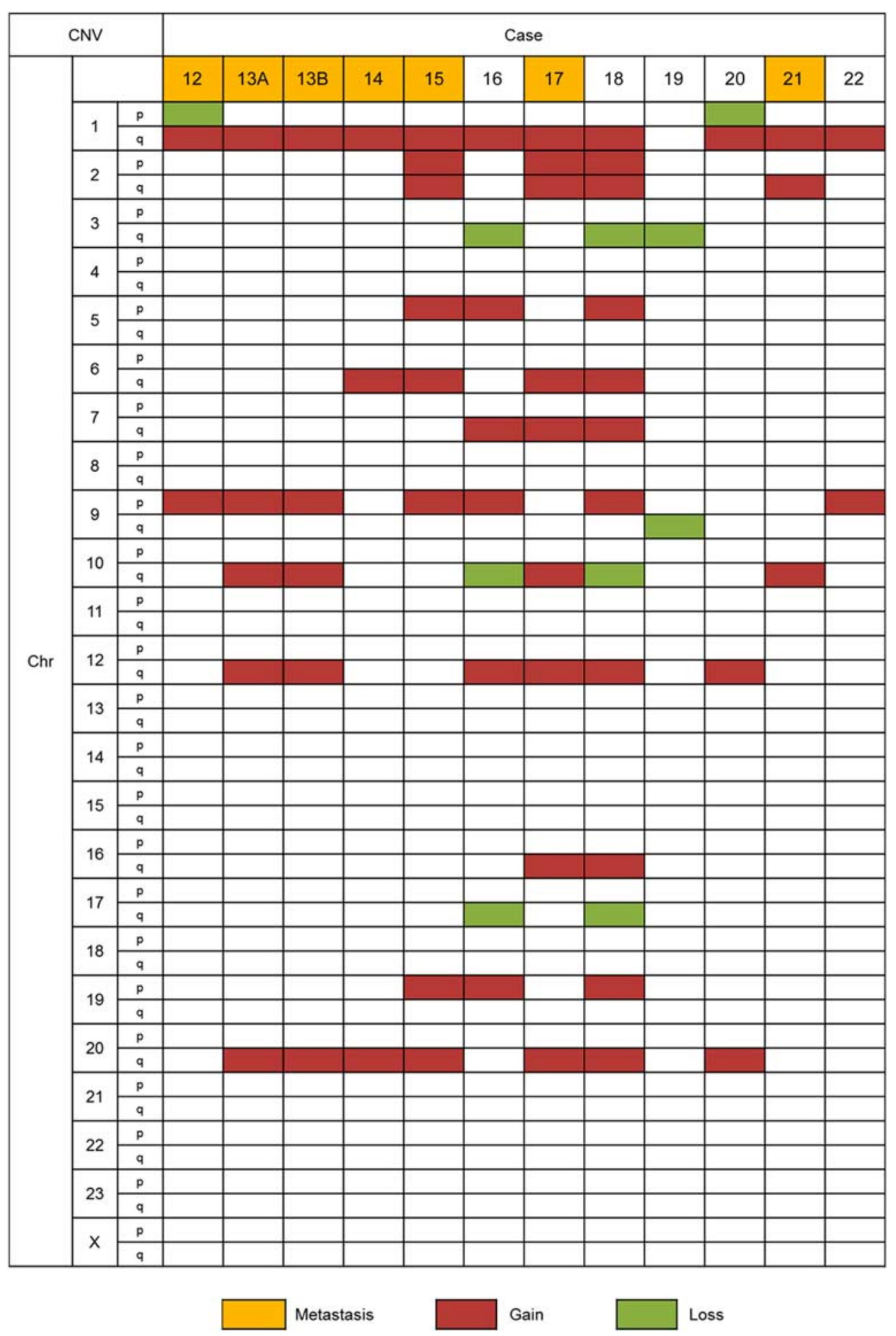

FIGURE 6. Summary of CNVs identified in 12 UB-MNACs by NGS. Each column represents a case, and each row represents a chromosome.

UC or corpus. In addition, we found that $9 / 12$ cases harbored $A R I D 1 A$ mutation. In line with this finding, Mirkovic et $\mathrm{al}^{20}$ reported $A R I D 1 A$ mutation in 6/17 cases. The most common $A R I D 1 A$ mutation in UB-MNAC was T294P, which has been also reported in endometrial endometrioid carcinoma, serous carcinoma, and carcinosarcoma. ${ }^{31}$ Two ARIDIA mutations
(Q288P and Q287Pfs) identified in this study were novel missense mutations.

Gain of $1 \mathrm{q}$ was the most common $\mathrm{CNV}$, detected in $11 / 12$ UB-MNACs. This finding is in agreement with that of Mirkovic et al, ${ }^{20}$ who detected $1 \mathrm{q}$ gain in $12 / 17$ cases of MNAC. In fact, 1q gain is the most common chromosomal 
alteration across all types of endometrial carcinoma. ${ }^{32} \mathrm{We}$ found $1 \mathrm{p}$ loss in $2 / 11$ cases with $1 \mathrm{q}$ gain. This finding is consistent with a previous report in which $2 / 3$ cases with $1 \mathrm{q}$ gain had $1 \mathrm{p}$ loss. ${ }^{20}$ Moreover, the fact that we identified 10q gain exclusively in cases associated with metastasis is consistent with the finding of Mirkovic et $\mathrm{al}^{20}$ of gain of chromosome 10 in 3 cases with metastasis, supporting the notion that gain of chromosome 10 may be an indicator of aggressive biological behavior of MNAC.

One case in our cohort lacked both KRAS and $A R I$ $D 1 A$ mutations. Three cases of UC-MNAC lacking both of $K R A S$ and ARIDIA mutations have been reported. ${ }^{20}$ Three of these 4 MNACs lacking both KRAS and ARIDIA mutations exhibited 1q gain. We found that our case was the only one arising from the UB and displaying lung metastasis. However, we could not identify histopathologic discriminators because of insufficient available information on the previously reported 3 MNACs. The nature and biological behavior of KRAS-wild type/ARID1A-wild type MNAC would be clarified if such cases are accumulated.

In summary, we comprehensively analyzed clinicopathologic and molecular characteristics of UBMNAC. Our observations indicate that UB-MNAC displays an aggressive biological behavior, with a tendency to metastasize to the lungs. Adverse pathologic characteristics, including large tumor size, ill-defined tumor border, presence of coagulative tumor cell necrosis, high mitotic activity, extrauterine extension, and presence of lymphovascular invasion, are likely to reflect the aggressive nature of UB-MNAC. NGS data revealed distinct molecular features of UB-MNAC, including frequent somatic mutations of KRAS and ARIDIA and gain of 1q.

\section{REFERENCES}

1. Ferry JA, Scully RE. Mesonephric remnants, hyperplasia, and neoplasia in the uterine cervix. A study of 49 cases. Am J Surg Pathol. 1990;14:1100-1111.

2. Clement PB, Young RH, Keh P, et al. Malignant mesonephric neoplasms of the uterine cervix. A report of eight cases, including four with a malignant spindle cell component. Am J Surg Pathol. 1995;19:1158-1171.

3. Roma AA, Goyal A, Yang B. Differential expression patterns of GATA3 in uterine mesonephric and nonmesonephric lesions. Int $J$ Gynecol Pathol. 2015;34:480-486.

4. Roma AA. Mesonephric carcinosarcoma involving uterine cervix and vagina: report of 2 cases with immunohistochemical positivity for PAX2, PAX8, and GATA-3. Int J Gynecol Pathol. 2014;33:624-629.

5. McFarland M, Quick CM, McCluggage WG. Hormone receptornegative, thyroid transcription factor 1-positive uterine and ovarian adenocarcinomas: report of a series of mesonephric-like adenocarcinomas. Histopathology. 2016;68:1013-1020.

6. Howitt BE, Emori MM, Drapkin R, et al. GATA3 is a sensitive and specific marker of benign and malignant mesonephric lesions in the lower female genital tract. Am J Surg Pathol. 2015;39:1411-1419.

7. Wepfer JF, Boex RM. Mesonephric duct remnants (Gartner's duct). Am J Roentgenol. 1978;131:499-500.

8. Tekin L, Yazici A, Akbaba E, et al. Mesonephric adenocarcinoma of the uterine cervix: a case report and review of the literature. $J$ Pak Med Assoc. 2015;65:1016-1017.

9. Dierickx A, Goker M, Braems G, et al. Mesonephric adenocarcinoma of the cervix: case report and literature review. Gynecol Oncol Rep. 2016;17:7-11.

10. Yamamoto Y, Akagi A, Izumi K, et al. Carcinosarcoma of the uterine body of mesonephric origin. Pathol Int. 1995;45:303-309.
11. Ordi J, Nogales FF, Palacin A, et al. Mesonephric adenocarcinoma of the uterine corpus: CD10 expression as evidence of mesonephric differentiation. Am J Surg Pathol. 2001;25:1540-1545.

12. Montagut C, Marmol M, Rey V, et al. Activity of chemotherapy with carboplatin plus paclitaxel in a recurrent mesonephric adenocarcinoma of the uterine corpus. Gynecol Oncol. 2003;90:458-461.

13. Bague S, Rodriguez IM, Prat J. Malignant mesonephric tumors of the female genital tract: a clinicopathologic study of 9 cases. $\mathrm{Am} \mathrm{J}$ Surg Pathol. 2004;28:601-607.

14. Marquette A, Moerman P, Vergote I, et al. Second case of uterine mesonephric adenocarcinoma. Int J Gynecol Cancer. 2006;16:1450-1454.

15. Wani Y, Notohara K, Tsukayama C. Mesonephric adenocarcinoma of the uterine corpus: a case report and review of the literature. Int $J$ Gynecol Pathol. 2008;27:346-352.

16. Wu H, Zhang L, Cao W, et al. Mesonephric adenocarcinoma of the uterine corpus. Int J Clin Exp Pathol. 2014;7:7012-7019.

17. Kim SS, Nam JH, Kim GE, et al. Mesonephric adenocarcinoma of the uterine corpus: a case report and diagnostic pitfall. Int $J$ Surg Pathol. 2016;24:153-158.

18. Zhao J, Liu C, Qi JI, et al. Mesonephric carcinoma of the uterine corpus: a report of two cases. Oncol Lett. 2016;11:335-339.

19. Mueller I, Kametriser G, Jacobs VR, et al. Mesonephric adenocarcinoma of the vagina: diagnosis and multimodal treatment of a rare tumor and analysis of worldwide experience. Strahlenther Onkol. 2016;192:668-671.

20. Mirkovic J, Sholl LM, Garcia E, et al. Targeted genomic profiling reveals recurrent KRAS mutations and gain of chromosome $1 \mathrm{q}$ in mesonephric carcinomas of the female genital tract. Mod Pathol. 2015;28:1504-1514.

21. Fregnani JH, Soares FA, Novik PR, et al. Comparison of biological behavior between early-stage adenocarcinoma and squamous cell carcinoma of the uterine cervix. Eur J Obstet Gynecol Reprod Biol. 2008:136:215-223.

22. Kenny SL, McBride HA, Jamison J, et al. Mesonephric adenocarcinomas of the uterine cervix and corpus: HPV-negative neoplasms that are commonly PAX8, CA125, and HMGA2 positive and that may be immunoreactive with TTF1 and hepatocyte nuclear factor 1-beta. Am J Surg Pathol. 2012;36:799-807.

23. Darragh TM, Colgan TJ, Thomas Cox J, et al. The Lower Anogenital Squamous Terminology Standardization project for HPV-associated lesions: background and consensus recommendations from the College of American Pathologists and the American Society for Colposcopy and Cervical Pathology. Int J Gynecol Pathol. 2013;32:76-115.

24. Rhead B, Karolchik D, Kuhn RM, et al. The UCSC Genome Browser database: update 2010. Nucleic Acids Res. 2010;38:D613-D619.

25. Mills RE, Luttig CT, Larkins CE, et al. An initial map of insertion and deletion (INDEL) variation in the human genome. Genome Res. 2006; 16:1182-1190.

26. Harano K, Hirakawa A, Yunokawa M, et al. Prognostic factors in patients with uterine carcinosarcoma: a multi-institutional retrospective study from the Japanese Gynecologic Oncology Group. Int $J$ Clin Oncol. 2016;21:168-176.

27. Labi FL, Evangelista S, Di Miscia A, et al. FIGO stage I endometrial carcinoma: evaluation of lung metastases and followup. Eur J Gynaecol Oncol. 2008;29:65-66.

28. Kounelis S, Kapranos N, Kouri E, et al. Immunohistochemical profile of endometrial adenocarcinoma: a study of 61 cases and review of the literature. Mod Pathol. 2000;13:379-388.

29. Chiesa-Vottero AG, Malpica A, Deavers MT, et al. Immunohistochemical overexpression of p16 and p53 in uterine serous carcinoma and ovarian high-grade serous carcinoma. Int J Gynecol Pathol. 2007;26:328-333.

30. Vang R, Whitaker BP, Farhood AI, et al. Immunohistochemical analysis of clear cell carcinoma of the gynecologic tract. Int J Gynecol Pathol. 2001;20:252-259.

31. McConechy MK, Ding J, Cheang MC, et al. Use of mutation profiles to refine the classification of endometrial carcinomas. $J$ Pathol. 2012;228:20-30.

32. Micci F, Teixeira MR, Haugom L, et al. Genomic aberrations in carcinomas of the uterine corpus. Genes Chromosomes Cancer. 2004; 40:229-246. 